genotypes were identified had genotype II alone or in combination with other types, and the high frequency of type II genotype is in keeping with the prevalence in Italy. ${ }^{13}$ Thus, HCV infection in patients with IPF is not associated with specific genotypes. Thirdly, in two patients a combination of two and three genotypes was present, a rare association in a single patient and almost exclusively confined to cases who have received multiple transfusions. ${ }^{12}$

This work was in part supported by grant "ex-60\%" from Ministero dell'Università e della Ricerca Scientifica e Tecnologica (MURST) to Riccardo Meliconi.

1 King TE. Idiopathic pulmonary fibrosis. In: Schwarz MI, King TE, eds. Interstitial lung disease. St Louis: Mosby King TE, eds. Interstitial lun

2 Prieto J, Sandro B, Beloqui O. Ribavirin in desquamative interstitial pneumonia. Chest 1988;93:446-7.

3 Agusti C, Xaubet A, Ballester E, Alarcòn A, Picado C. Aerosolized ribavirin in patients with advanced cryptogenic fibrosing alveolitis: a pilot study. Thorax 1993;48 68-9.

4 Ueda T, Ohfa K, Suzuki N, Yamaguchi M, Hirai K, Hosiuchi $\mathrm{T}$, et al. Idiopathic pulmonary fibrosis and high prevalence of serum antibodies to hepatitis $\mathrm{C}$ virus. $\mathrm{Am}$ Rev Respir Dis 1992;146:266-8.

5 Irving WL, Day S, Johnston DA. Idiopathic pulmonary fibrosis and hepatitis C virus infection. Am Rev Respir Dis fibrosis and hepatit

6 Webb Wr, Müller WL, Naldich DP. High resolution CT of the lung. New York: Raven Press, 1992:57-9.

7 Ravaggi A, Primi D, Cariani E. Direct PCR amplification of HCV RNA from human serum. PCR Methods Appl 1993;1:291-2.

8 Okamoto H, Kurai K, Okada S-I, Yamamoto K, Lizuka $\mathrm{H}$ Tanaka $\mathrm{T}$, et al. Full-length sequence of a hepatitis $\mathrm{C}$ virus genome having poor homology to reported isolates: comparative study of four distinct genotypes. Virology 1992;188:331-41.

9 Silini E, Bono F, Cerino A, Piazza V, Solcia E, Mondelli MU. Virological features of hepatitis C virus infection in hemodialysis patients. F Clin Microbiol 1993;31:2913-7.

10 Bellentani S, Tíribelli C, Saccoccio G, Sodde M, Fratti N, De Martin C, et al. Prevalence of chronic liver disease in the general population of Northern Italy: the Dionysos study. Hepatology 1994;20:1442-9.

11 Baraldini M, Miglio F, Pirillo L, Cursaro C, Meliconi R, Stefanini GF, et al. Hepatitis B virus markers in hematologic patients: relation to transfusion treatment and hospitalization. Vox Sang 1983;45:112-20.

12 Ichimura H, Tamura I, Kurimura O, Koda T, Mizui M, Tsuchie $\mathrm{H}$, et al. Hepatitis $\mathrm{C}$ virus genotypes, reactivity to recombinant immunoblotting assay 2 antigens and liver disease. $\mathcal{F}$ Med Virol 1994;43:212-5.

13 Dusheiko G, Schmilovitz-Weiss H, Brown D, McOmish F, Yap PL, Sherlock S, et al. Hepatitis C virus genotypes: an investigation of type-specific differences in geographic origin and disease. Hepatology 1994;19:13-8.

\title{
Use of tracheal auscultation for the assessment of bronchial responsiveness in asthmatic children
}

\author{
Aline B Sprikkelman, Marion H Grol, Marlies S Lourens, Jorrit Gerritsen, \\ Hugo S A Heymans, Wim M C van Aalderen
}

respiratory rate, and/or prolonged expiration. In two subjects altered lung sounds were detectable one dose step before $\mathbf{P D}_{20}$ was reached. In three cases in whom no fall in $\mathrm{FEV}_{1}$ occurred, no change in lung sounds could be detected at the highest methacholine dose.

Conclusion - Changes in lung sounds correspond well with a $20 \%$ fall in $\mathrm{FEV}_{1}$ after methacholine challenge. Wheeze is an insensitive indicator for assessing bronchial responsiveness. Cough, increase in respiratory rate, and prolonged expiration occurs more frequently.

(Thorax 1996;51:317-319)

Keywords: bronchial responsiveness, lung sounds, children

Measurement of bronchial responsiveness to methacholine has been useful in the diagnosis, assessment of severity, and follow up of asthma, but some children are not able to perform spirometric tests reliably. ${ }^{1}$ A method based on detecting audible wheeze over the trachea and requiring passive cooperation only has been described for bronchial challenge with methacholine in children. ${ }^{2}$ In older children a close correlation has been observed between the $20 \%$ fall in forced expiratory volume in one second expiration were assessed. choline dose causing a fall in $F E V_{1}$ of $20 \%$ or more $\left(\mathbf{P D}_{20}\right)$ was detected in 12 children wheeze and in eight by cough, increased
\end{abstract}


Characteristics of patients and results of lung function testing

\begin{tabular}{|c|c|c|c|c|c|}
\hline \multirow{2}{*}{$\begin{array}{l}\text { Patient } \\
\text { no. }\end{array}$} & \multirow{2}{*}{$\begin{array}{l}\text { Age } \\
\text { (years) }\end{array}$} & \multirow{2}{*}{$\begin{array}{l}F E V_{t} / V C \\
(\%)\end{array}$} & \multicolumn{2}{|c|}{ Methacholine $(\mathrm{mg} / \mathrm{ml})$} & \multirow[t]{2}{*}{ Lung sounds } \\
\hline & & & $P D_{20}$ & PDwheeze & \\
\hline 1 & 10 & 86 & $1 \cdot 2$ & $1 \cdot 2$ & Cough \\
\hline 2 & 12 & 71 & 0.6 & $0 \cdot 6$ & Wheeze \\
\hline 3 & 11 & 75 & $4 \cdot 9$ & $4 \cdot 9$ & Cough \\
\hline 4 & 9 & 77 & $>39 \cdot 3$ & $>39 \cdot 3$ & None \\
\hline 5 & 10 & 77 & $1 \cdot 2$ & $1 \cdot 2$ & Increased respiratory rate \\
\hline 6 & 15 & 60 & 0.6 & $0 \cdot 3$ & Wheeze \\
\hline 7 & 11 & 76 & $39 \cdot 3$ & $39 \cdot 3$ & Wheeze \\
\hline 8 & 9 & 90 & $19 \cdot 6$ & $9 \cdot 8$ & Cough, increased respiratory rate \\
\hline 9 & 12 & 86 & $2 \cdot 5$ & $2 \cdot 5$ & Cough, prolonged expiration \\
\hline 10 & 9 & 84 & $4 \cdot 9$ & $4 \cdot 9$ & Wheeze \\
\hline 11 & 12 & 82 & 4.9 & $4 \cdot 9$ & Cough \\
\hline 12 & 10 & 64 & $>39 \cdot 3$ & $>39 \cdot 3$ & None \\
\hline 13 & 8 & 93 & $9 \cdot 8$ & $9 \cdot 8$ & Increased respiratory rate \\
\hline 14 & 11 & 78 & $1 \cdot 2$ & $1 \cdot 2$ & Cough, prolonged expiration \\
\hline 15 & 13 & 90 & $>39 \cdot 3$ & $>39 \cdot 3$ & None \\
\hline
\end{tabular}

$\mathrm{FEV}_{1}=$ forced expiratory volume in one second; $\mathrm{VC}=$ vital capacity $\mathrm{PD}_{20}=$ dose of methacholine causing a $20 \%$ fall in $\mathrm{FEV}_{1}$; $\mathrm{PD}$ wheeze $=$ dose of methacholine at which change in lung sounds was heard. a calibrated output of $5.0 \mu \mathrm{l}$ per puff. The DeVilbiss nebuliser was attached to a French Rosenthal dosimeter. During each inhalation of the aerosol a deep breath was taken and held for 10 seconds. The aerosol was delivered into the mouth piece and a nose clip was applied. Three minutes after the fourth inhalation of the diluent $\mathrm{FEV}_{1}$ measurements were performed. Each methacholine concentration was given at five minute intervals. The tests were discontinued if $\mathrm{FEV}_{1}$ decreased by $20 \%$ or more from the baseline or when the maximum dose of methacholine was reached. Bronchial responsiveness was defined as the total cumulative dose of methacholine inducing a $20 \%$ or more fall in $\mathrm{FEV}_{1}\left(\mathrm{PD}_{20}\right)$.

$\left(\mathrm{FEV}_{1}\right)$ after inhaling methacholine $\left(\mathrm{PC}_{20}\right)$ and the occurrence of wheeze. ${ }^{23}$ It was reported recently that the auscultation method is potentially dangerous because significant falls in transcutaneous oxygen tension sometimes occur in the absence of wheeze. ${ }^{4}$

Since the results of studies that use audible wheeze as an indicator of bronchial responsiveness during challenge tests are controversial, we investigated in a pilot study whether a change in lung sounds corresponded to a $20 \%$ fall in $\mathrm{FEV}_{1}$ after methacholine challenge in asthmatic children, and whether the occurrence of wheeze was the most important change.

\section{Methods}

SUBJECTS

Fifteen asthmatic children (eight boys) aged 8-15 years (mean 10.8 years) were recruited from our outpatient clinic. The mean baseline Tiffeneau index $\left(\mathrm{FEV}_{1} / \mathrm{IVC}\right)$ before the methacholine challenge test was $79 \%$ of predicted (range 60-93). All children had normal chest auscultation before the challenge test. Bronchial challenge with methacholine was requested as part of their routine evaluation and consent of the child and parents was obtained. Sympathomimetic bronchodilator therapy was withheld for at least eight hours (short acting) or 24 hours (long acting) before testing and antihistamines for one week. Inhaled corticosteroids and sodium cromoglycate were continued. The study was approved by the medical ethics committee of our hospital.

\section{INHALATION CHALLENGE TEST}

The children performed spirometric tests using a water sealed spirometer (Lode, Groningen, The Netherlands). The best result of three $\mathrm{FEV}_{1}$ attempts was used for analysis. Methacholine inhalation challenge was preceded by baseline lung function measurements, followed immediately by inhalation of saline control. After inhalation of saline doubling concentrations of methacholine (beginning with $0.15 \mathrm{mg} / \mathrm{ml}$ to a maximum of $39.3 \mathrm{mg} / \mathrm{ml}$ ) were delivered during four inhalations via a gauged DeVilbiss nebuliser model 646, with

\section{TRACHEAL AUSCULTATION}

A microphone (Wip en Broos, Winsum, The Netherlands) was placed in the suprasternal notch and lung sounds were recorded over the trachea for one minute starting two minutes after administration of each dose of methacholine during quiet respiration. The microphone was attached to the skin with two sided adhesive tape rings. Lung sounds were stored on tape (DT-120 Rn, Sony), using a digital audio tape recorder (DTC-59 ES, Sony) and were analysed by headphone (Beyer Dynamic DT 801). The lung sounds were scored directly as wheeze, cough, prolonged expiration, and increase in respiratory rate. Cough was scored if it was persistent, and prolonged expiration was scored when the duration of expiration exceeded the duration of inspiration. Increase in respiratory rate was defined as an increase of $50 \%$ or more from baseline respiratory rate. A second analysis of the lung sounds was blindly scored from the audio tape recordings by another physician who was unaware of patient characteristics, baseline lung function, and the methacholine concentrations. During this second analysis lung sounds of all children were successively recorded on one tape and no indication of the start and ending of the challenges was given. The total cumulative methacholine dose at which a change in lung sounds was heard was

\section{Results}

The results of the study are presented in the table. In 12 of the 15 children the methacholine $\mathrm{PD}_{20}$ was detected by the change in lung sounds - in four by wheeze and in eight by cough, prolonged expiration, and/or increased respiratory rate. In two children lung sounds were detectable one dose step before the $\mathrm{PD}_{20}$ was reached. In three of 15 children in whom no change in lung sounds could be detected there was no fall in $\mathrm{FEV}_{1}$ on the highest methacholine dose.

Total agreement was found between the lung sounds scored directly and the lung sounds scored blindly during the subsequent audio tape recording analysis. defined as PDwheeze. 


\section{Discussion}

Changes in lung sounds were found to correspond well with a $20 \%$ fall in $\mathrm{FEV}_{1}$ after methacholine challenge. In contrast with earlier studies $^{23}$ in which wheeze was the indicator of bronchial responsiveness, we found wheeze by itself to be a poor indicator for assessing bronchial responsiveness. Cough, increase in respiratory rate, and prolonged expiration were more frequently found.

Noviski et $a l^{\beta}$ observed that transient coughing, increase in respiratory rate, mild wheezing over the lung fields, and localised crepitations in some patients did not correlate with either the concentration of methacholine causing wheezing or the concentration causing the $\mathrm{FEV}_{1}$ to fall by $20 \%$.

Avital et al concluded that wheeze was present in almost every child who was challenged and had a fall in $\mathrm{FEV}_{1}$ of more than $20 \%$. The discrepancies between our results and the observations of this group may be explained by the fact that they do not state what the real fall in $\mathrm{FEV}_{1}$ was after the challenge. It might well be that the actual fall in $\mathrm{FEV}_{1}$ was far greater than $20 \%$.

Our observation that wheeze by itself is not sensitive for assessing the response to a methacholine challenge is in accordance with Wilson et $a l^{4}$ who compared three techniques for measuring bronchial responsiveness in young children. They also reported that most of the children coughed after methacholine at doses which were associated with a fall in transcutaneous oxygen tension. Because Wilson et al did not investigate $\mathrm{FEV}_{1}$, it is not clear whether this coughing would have corresponded with a fall in $\mathrm{FEV}_{1}$ of $20 \%$. In contrast with our findings, Wilson et al ${ }^{4}$ stated that the auscultation method is unreliable and potentially dangerous. They observed that significant falls in transcutaneous oxygen tension sometimes occurred in the absence of wheeze. However, four of their children showed signs of respiratory distress. In our study none of the children showed signs of dyspnoea, cyanosis, or intercostal retractions. The differences in the results could thus be due to differences in study populations. Only 11 of the 30 children studied by Wilson et al were considered to have asthma, whereas our group consisted only of asthmatic children.

In conclusion, changes in lung sounds are easy to detect over the trachea and correspond well with a $20 \%$ fall in $\mathrm{FEV}_{1}$ after methacholine challenge. Computerised analysis of changes in lung sounds may provide a more objective method in situations where this warrants the cost. ${ }^{5}$ For routine clinical assessment of bronchial responsiveness in asthmatic children changes in lung sounds can be used provided that attention is paid, not only to the occurrence of wheeze, but also to cough, increase in respiratory rate, and a prolonged expiration.

This study was supported by the Dutch Asthma Foundation. The authors wish to thank Dr A E J Dubois for assistance with the English of this paper.

1 Kanengiser S, Dozor AJ. Forced expiratory maneuvers in children aged 3 to 5 years. Pediatr Pulmonol 1994;18:144-9.

2 Avital A, Bar-Yisahay E, Springer C, Godfrey S. Bronchia provocation tests in young children using tracheal auscultation. 7 Pediatr 1988;112:591-4.

3 Noviski N, Cohen L, Springer C, Bar-Yishay E, Godfrey S. Bronchial provocation determined by breath sounds compared with lung function. Arch Dis Child1991;66:952-5.

4 Wilson NM, Bridge P, Phagoo SB, Silverman M. The measurement of methacholine responsiveness in 5 year old measurement of methacholine responsiveness in 5 year old
children: three methods compared. Eur Respir $\mathcal{F} 1995 ; 8$ : children

5 Beck R, Dickson U, Montgomery MD, Mitchell I. Histamine challenge in young children using computerized lung sounds analysis. Chest 1992;102:759-63. 